\title{
TACKLING KIRKPATRICK: CREATING AND IMPROVING A FIRST- YEAR ELECTROMAGNETICS ACTIVITY
}

\author{
Derek Wright \\ Faculty of Engineering, University of Waterloo \\ derek.wright@uwaterloo.ca
}

\begin{abstract}
At the University of Waterloo, $1 B$ electrical and computer engineering students participate in a series of hands-on, open-ended design activities. In particular, a wind-your-own motor activity has been trialed on four occasions. The activity is widely recognized as being fun, but are the students designing or kludging? The Kirkpatrick Model of Training Evaluation was used as a framework to assess student perceptions of the activity and to guide focus group discussions. The activity was iteratively improved to maintain a positive reaction while increasing student learning.
\end{abstract}

Keywords: Kirkpatrick Model, Kolb Learning Styles, Experiential Learning

\section{INTRODUCTION}

The Department of Electrical and Computer Engineering (ECE) at the University of Waterloo hosts a two-day event for 1B students called ECE Design Days. The purpose of the event is to a) improve social and academic engagement between students and the department, b) provide formative opportunities to practice open-ended engineering design, c) integrate knowledge from across the curriculum, and, d) improve student critical thinking.

Furthermore, direct and indirect assessment of incoming ECE students shows and increasing lack of hands-on experience before beginning their undergraduate program. The well-established Kolb learning cycle [1] has been adapted for such activities in higher education [2]. Experiential learning that progresses through the Kolb learning cycle can be more impactful than regular lectures and labs alone [3]. Therefore, ECE Design Days was planned to move students through the learning cycle, especially through the active experimentation and concrete experience portions that are often lacking in typical engineering lectures.

ECE Design Days consists of four hands-on activities that integrate knowledge from across their first-year curriculum. It is formative in the sense that they are rewarded for effort and not penalized for failure. The ECE Design Days event was piloted in the Winter and Spring
2017, and Winter and Spring (planned) 2018 terms on six cohorts of 1B ECE students. Faculty, staff, and upperyear student volunteers supervised the event and assisted students when problems landed too far outside the scope of their experience. Participation of these stakeholders also builds department culture and sets an institutional expectation for participation in the development and execution of ECE Design Days [4].

Project-based learning principles were adopted as they have been shown to provide numerous benefits, including improving student learning [5]. As such, the four activities revolve around the common thread of developing a mobile robotic pitching machine. Students completed the activities in groups of four. The first three were a D.I.Y. DC motor, an H-Bridge circuit, and an embedded programming challenge. The fourth activity has students select from software or robotics based on their interests. At the end, the final part of ECE Design Days is called "Do Something Amazing," and is a creative free-for-all.

This paper focuses on the D.I.Y. DC motor activity, which has students hand-wind $2 \mathrm{~m}$ of magnetic wire into a small DC motor. Students use sandpaper to expose the conductor along one-half of the wire circumference on each end, which acts in lieu of a commutator. The winding is suspended from paperclips with a permanent magnet underneath. The paper clips are connected to a DC power supply and the motor spins, though usually after quite a lot of manual tweaking. The students try to maximize the speed of their motor.

The Kirkpatrick Model of Training Evaluation [6][7][8] has been successfully used to assess ECE learning activities [9]. The model was used to evaluate the effectiveness of ECE Design Days activities. It consists of four levels that characterize the impact of an educational experience: Reaction, Learning, Behaviour, and Return on Investment. Reaction refers to the emotional response of participants, whereas Learning refers to the degree to which participants' knowledge and skills improved. Behaviour and Return on Investment are longer-term considerations outside the scope of this our evaluation.

Results of indirect assessment (student surveys and faculty volunteer focus groups) show that the activities 
are fun, but are they really learning anything? Are students designing anything, or merely hacking at a solution until it works?

\section{EVOLUTION OF THE MOTOR ACTIVITY}

During the Winter and Spring 2017 offerings, students were given the motor materials during the event itself and asked to construct a DC motor with no other instructions. They were encouraged to look for answers online, as occurs in the workplace. Fig. 1 shows that students enjoyed the activity (positive reaction) and believed that it was a valuable learning experience (positive perceived learning).

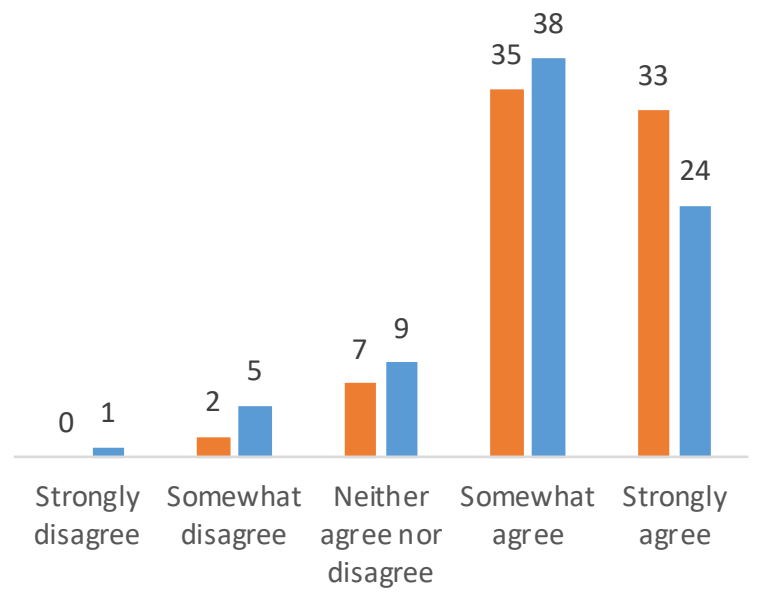

I enjoyed the $\mathrm{H}$-Bridge activity

The $\mathrm{H}$-Bridge activity was a valuable experience

Fig. 1 - Winter 2017 student feedback concerning Reaction and perceived Learning.

However, experienced faculty volunteers noted that the students did very little design and analysis during the motor winding activity of both pilots. They mostly wound the wire without choosing a particular loop diameter and fidgeted with it until it worked. This approach is not indicative of achieving the intended learning in design, analysis, and critical thinking. Many groups were unable to produce a functioning motor, and many students could not explain why the motor worked or did not. Therefore, the challenge was to modify the activity to achieve more profound learning without sacrificing the positive reaction.

To force students to design their motors, the activity was reworked to include analytical modeling to maximize the motor performance. However, a model detailed enough to find a reasonable motor winding diameter is complicated. As a test of the viability, the information in Appendix A was given to a group of four $1 \mathrm{~B}$ co-op students working at the university along with instructions on how to create such a model. The task was too complicated for the students to complete and they did not enjoy the activity at all.

As a compromise, students participating in the Winter 2018 ECE Design Days were given the information in Appendix A along with the instructions in Appendix B one week ahead of the event. In contrast to the 2017 events, the students were all able to produce a spinning motor, and faculty volunteers reported significantly improved understanding of the physics at play.

\section{CONCLUSIONS}

We were able to improve the motor activity by applying the Kirkpatrick model to separate student reaction and learning into independent outcomes. The next offering of ECE Design Days is in the Spring 2018 term. Based on the success of using the Kirkpatrick model to improve the learning of the motor activity without sacrificing reaction, the other activities are being modified to increase their design and critical thinking aspects.

\section{Acknowledgements}

We acknowledge the support of the Natural Sciences and Engineering Research Council of Canada (NSERC). Cette recherche a été financée par le Conseil de recherches en sciences naturelles et en génie du Canada (CRSNG). We also acknowledge the support of the Faculty of Engineering and the Department of Electrical and Computer Engineering at the University of Waterloo.

\section{References}

[1] Alice Y Kolb, "The Kolb learning style inventoryversion 3.12005 technical specifications," in Learning Styles Inventory Technical Manual. Hay Resource Direct, 2005, $71 \mathrm{pp}$.

[2] Alice Y Kolb and David A. Kolb. "Learning styles and learning spaces: Enhancing experiential learning in higher education," Academy of Management Learning and Education, vol. 4, no. 2, pp. 193-212, 2005

[3] Manilla D. Svinicki and Nancy M. Dixon, "The Kolb model modified for classroom activities." College Teaching, vol. 35, no. 4, pp. 141-146, 1987

[4] Felder, Richard M., Rebecca Brent, and Michael J. Prince. "Engineering instructional development: Programs, best practices, and recommendations," Journal of Engineering Education vol. 100, no. 1 pp. 89-122, 2011.

[5] Clive L Dym, Alice M. Agogino, Ozgur Eris, Daniel D. Frey, and Larry J. Leifer. "Engineering design thinking, teaching, and learning," Journal of Engineering Education, vol. 94, no. 1, pp. 103-120, 2005 
[6] Donald Kirkpatrick, "Revisiting Kirkpatrick’s fourlevel-model," Training and Development, vol. 50, no. 1, pp. 54-57., 1996

[7] James D. Kirkpatrick and Wendy Kayser Kirkpatrick, Kirkpatrick's Four Levels of Training Evaluation. Association for Talent Development; 2016 (1 $1^{\text {st }}$ ed.), 200 pp. \{ISBN: 978-1607-28008-8\}

[8] Walter Dick and R. Burke Johnson, "Evaluation in instructional design: The impact of Kirkpatrick's fourlevel model," in Trends and issues in instructional design and technology. Pearson, 2006 ( $2^{\text {nd }}$ ed.), pp. 145-153 \{ISBN: 978-0131-70805-1\}

[9] J. Olin Campbell, John R. Bourne, Pieter J. Mosterman, and Arthur J. Brodersen, "The effectiveness of learning simulations for electronic laboratories," Journal of Engineering Education, vol. 91, no. 1, pp. 81-87, 2002

\section{APPENDIX A: PHYSICAL MODEL DETAILS}
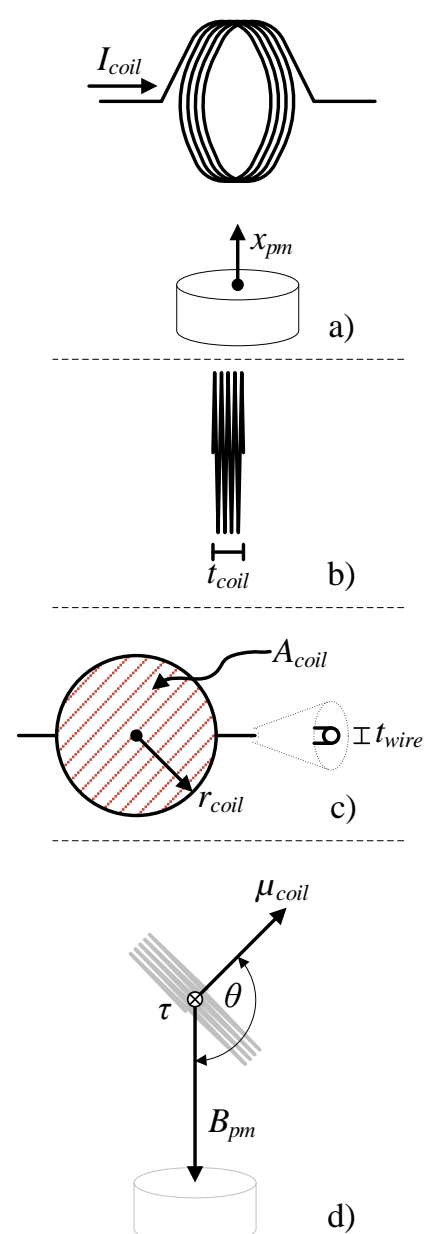

Fig. 2 Hand-wound DC motor physical model diagrams: a) Perspective view showing the wound coil overtop a permanent magnet; b) Side view showing wound coil thickness; c) Front view showing coil area and wire thickness; and d) Front view showing the aligning torque vector.
Table 1 - Parameters and variables for the model in Fig. 2

\section{Parameter Description [units]}

$\boldsymbol{t}_{\text {wire }} \quad$ Thickness of the magnetic wire [m]

$\boldsymbol{l}_{\text {wire }} \quad$ Length of the magnetic wire [m]

$\boldsymbol{N}_{\text {coil }} \quad$ Number of turns of magnetic wire in the

coil $(\mathrm{N}=4.5$ shown in the figure)

$\boldsymbol{r}_{\text {coil }} \quad$ Radius of the coil [m]

$\boldsymbol{A}_{\text {coil }} \quad$ Cross-sectional area of the coil $\left[\mathrm{m}^{2}\right]$

$\boldsymbol{t}_{\text {coil }} \quad$ Thickness of the coil [m]

$I_{\text {coil }} \quad$ Current into the coil [A]

$\boldsymbol{x}_{\boldsymbol{p m}} \quad$ Distance normal to the surface of the permanent magnet [m]

$\boldsymbol{B}_{\boldsymbol{p m}} \quad$ Magnetic flux density of the permanent magnet at a distance of $x_{p m}$ [T]

$\boldsymbol{\mu}_{\boldsymbol{p m}} \quad$ Magnetic moment of the permanent magnet (unknown constant) [N·m/T]

$\boldsymbol{\mu}_{0} \quad$ Magnetic permeability of free space $\left[4 \pi \times 10^{-7} \mathrm{~N} / \mathrm{A}^{2}\right]$

$\boldsymbol{\mu}_{\text {coil }} \quad$ Magnetic moment of the coil $[\mathrm{N} \cdot \mathrm{m} / \mathrm{T}]$

$\boldsymbol{\tau} \quad$ Aligning torque $[\mathrm{N} \cdot \mathrm{m}]$

$\boldsymbol{\theta} \quad$ Alignment angle [rad]

\section{APPENDIX B: SIMPLIFIED TEAM INSTRUCTIONS}

\section{Kit A Contents}

- 2 m of 24 AWG magnetic wire

- Eraser

- Permanent magnets

- Paper clips

- Sand paper

- Battery

\section{Activity Flow}

- $\quad$ Before ECE Design Days

o Using the supplies in Kit A, create a simple DC motor (some judicious Googling will help)

o Understand how and why it works

- During ECE Design Days

o Optimize the speed of your motor

o When you're ready, a Leader will come by with a standardized magnet and battery and you will measure your motor's RPM

\section{Goals}

- 1 ELECTRONS* for every 250 RPM achieved

- Extra ELECTRONS* for demonstrating excellent oscilloscope skills

- $\quad$ Extra ELECTRONS* for beating Derek Wright's $\max$ RPM

*An invented score-keeping currency 